ISSN 0258-7122

Bangladesh J. Agril. Res. 39(2): 373-383, June 2014

\title{
CHANGES IN PHYSICOCHEMICAL ATTRIBUTES OF SWEET PEPPER (Capsicum annum L.) DURING FRUIT GROWTH AND DEVELOPMENT
}

\author{
M. A. RAHMAN ${ }^{1}$, G. M. A. HALIM ${ }^{2}$, M. G. F. CHOWDHURY ${ }^{3}$ \\ M. A. HOSSAIN ${ }^{4}$ AND M. M. RAHMAN ${ }^{5}$
}

\begin{abstract}
Changes in physicochemical attributes of sweet pepper var. 'BARI Misti Morich-1' during fruit growth and development were studied. Capsicum flowers were tagged on the day of anthesis and fruits were harvested at three days interval started on 33 days after anthesis (DAA) until 48 DAA, when turned to light green colour. Length, diameter, and weight of fruits were linearly increased from 33 DAA to 48 DAA. Dry matter content, TSS, firmness, and shelf life of fruits were also gradually increased with lengthen the harvesting time from flower anthesis and reached from 5.1 to $7.3 \%, 4$ to $5 \%, 7.1$ to $14.5 \mathrm{kgf} \mathrm{cm}^{-2}$ and 9.6 days to 21.3 days, respectively, from 33 DAA to 48 DAA. However, ascorbic acid content of fruits was sharply decreased from 68 to $56 \mathrm{mg} / 100 \mathrm{~g}$ from first harvest to last harvest, respectively. Hue angle declined with time while chroma and lightness values increased with fruit maturity. Considering all physical and nutritional characteristics and shelf life along with sensory evaluation scores, fruits of BARI Misti Morich-1 was found suitable to harvest after 45 days of anthesis, when they attained length $12.2 \mathrm{~cm}$, diameter $8.8 \mathrm{~cm}$, and weight $191 \mathrm{~g}$. Moreover, fruits were crispier, glossy with attractive colour and flavour and contained $58 \mathrm{mg} / 100 \mathrm{~g}$ ascorbic acid at this maturity stage.
\end{abstract}

Keywords: Fruit maturity, fruit development, postharvest quality, shelf life, capsicum.

\section{Introduction}

Sweet pepper (Capsicum annum L.) is one of the most important high value crop grown extensively throughout the world, especially in the temperate region. The crop is highly sensitive to environmental factors like temperature and solar radiation (Bhatt et al., 1999). However, efforts have been made for growing sweet pepper in the tropical and subtropical countries since last few years. In Bangladesh, some advanced farmers sporadically started to grow this crop to fulfill the local demand of urban areas (Saha and Salam, 2004).

Maturity is an integral component of produce quality particularly in the context of commercial maturity (Will et al., 1998). According to Bautista (1990) 'maturity index is the sign or indication of the readiness of fruits and vegetables

${ }^{1,4, \& 5}$ Senior Scientific Officer, ${ }^{2}$ Principal Scientific Officer, Horticulture Research Centre, Bangladesh Agricultural Research Institute (BARI), ${ }^{3}$ Scientific Officer, Postharvest Technology Division, B ARI, Gazipur, Bangladesh. 
for harvest according to the consumer's choice'. Generally sweet pepper fruits are harvested at either the green mature or colouring stage. Usually field grown peppers are commercially harvested at the mature green stage (Lin et al., 1993). Precise determination of sweet pepper fruit maturity is difficult at harvest. Fruits are harvested at different degrees of maturity and a proportion of fruits may be immature. Thus, harvesting of pepper fruits of different maturity at the same time is a common problem even though fruits may have the same skin colour at harvest (Tadesse et al. 2002). If fruits are picked immature, they may stay green longer but may not develop acceptable colour and flavour upon ripening (Boonyakiat et al., 1987), which may lead to loss of consumer confidence. Moreover, since fruit growth continues until harvest, size of immature fruit will be smaller than more mature fruit resulting in a loss of harvest yield. Over matured fruit, on the other hand, lose their attractiveness and crispiness and become slimy in texture within very short time (Pareek, 2001). Therefore, determining the optimum maturity will benefit both consumer and grower. Normally, capsicum fruit maturity is assessed on the basis of subjective evaluations of visual colour (Lin et al., 1993; Sanchez et al., 1993; Howard et al., 1994), size, and hand press to evaluate firmness or days from anthesis (Manandhar et al., 1995; Sanchez et al., 1993). Thus, there is a need to develop optimum maturity and quality indices for sweet pepper that are objective and consistent more reliable than existing methods.

A little information is available on the physiology of fruit growth and maturity of sweet pepper (Serrano et al., 1995) and the changes of physicochemical attributes during maturation and ripening (Tadesse et al., 2002). However, significant physiological changes associated with maturation and ripening may occur before or after commercial harvest and different cultivars may behave differently.

For determining appropriate harvest time, different attributes like surface colour, fruit firmness, soluble solids content, acid content, and concentration of volatile compounds as well as changes in other chemical constituents are used as indicators (Tadesse et al. 2002) so that products develop acceptable taste and flavour characteristics as well as maintaining structural integrity during subsequent storage and/or shelf life (Meredith et al., 1989; Wills et al., 1998). The present experiment was undertaken to study the changes in physicochemical attributes of sweet pepper during fruit growth and development and to determine a reliable harvest maturity index for the fruit.

\section{Materials and Method}

Crop growing and cultural management: Sweet pepper fruits were obtained from field grown plants at experimental field of Horticulture Research Centre, BARI, Gazipur, Bangladesh. Seeds of sweet pepper var. 'BARI Misti Morich-1' 
were sown on 15 November 2010 in the seed bed. Seedlings with 2-3 leaf stage were transplanted into small plastic pots. Thirty five days old seedlings (4-5 true leaf stage) were then transplanted in the experimental plots. The experiment was carried out in a Randomized Complete Block Design with three replications. The unit plot size was $1 \mathrm{~m} \times 4 \mathrm{~m}$. Seedlings were placed in two rows of $50 \mathrm{~cm}$ apart with $50 \mathrm{~cm}$ between plants within a row to give a population of 16 plants/plot. Manure and chemical fertilizers were applied in the experimental plot as per recommendation (Saha and Salam 2004). The recommended dosage for one hectare area were $10 \mathrm{t}$ cow dung, $100 \mathrm{~kg} \mathrm{~N}, 150 \mathrm{~kg} \mathrm{P}_{2} \mathrm{O}_{5}, 120 \mathrm{~K}_{2} \mathrm{O}, 20 \mathrm{~kg} \mathrm{~S}$, and $04 \mathrm{~kg} \mathrm{Zn}$. Half the quantity of cowdung was applied during final land preparation. The remaining cow dung, the entire quantity of $\mathrm{P}_{2} \mathrm{O}_{5}, \mathrm{Zn}, \mathrm{S}$, and $1 / 3^{\text {rd }}$ each of $\mathrm{N}$ and $\mathrm{K}_{2} \mathrm{O}$ were applied in bed during pit preparation. The rest of $\mathrm{N}$ and $\mathrm{K}_{2} \mathrm{O}$ were top dressed in two equal splits after 25 and 50 days of transplantation. The intercultural operations, such as weeding, irrigation, and plant protection measures were taken as and when necessary.

Flower tagging and fruit harvest: Flowers were tagged at anthesis to determine the stage of fruit development and 20 randomly selected fruits from 20 plants were harvested at three days intervals started on 33 days after anthesis (DAA) until 48 DAA to determine their growth and maturity. At each harvesting date, out of 20 fruits, 10 were used to determine physicochemical properties like fruit length, diameter, weight, firmness, crispiness, fibrousness, external colour, taste, and flavour, dry matter content, TSS, ascorbic acid content, and $\mathrm{pH}$. The rest 10 fruits were packed in a $1 \%$ perforated polyethylene bag and held at $12{ }^{\circ} \mathrm{C}$ and 88 $\pm 5 \% \mathrm{RH}$ in a constant temperature and humidity chamber (Model: VS-9111H350 , Korea) to observe the shelf life.

Measurement of fruit weight, length, diameter and dry matter: Fruit weight was determined using a digital electronic balance (Mettler PJ400, Switzerland) after transporting the harvested fruit in a closed plastic bag to the laboratory. Fruit length and diameter were measured with digital vernire caliper. For quantifying the dry matter content, the samples were kept in an electric oven at $70{ }^{\circ} \mathrm{C}$ for about $48 \mathrm{~h}$ until a constant weight was achieved. Dry matter content was expressed as percentage which calculated based on its initial fresh weight.

Measurements of surface colour and flesh firmness: Surface colour of capsicum fruits was evaluated with a Chroma Meter (Model CR-400, Minolta Corp., and Japan). CIE $L * a * b *$ coordinates were recorded using D65 illuminants and a $10^{\circ}$ Standard Observer as a reference system. $L^{*}$ is lightness, $a^{*}$ (-reenness to + redness) and $b^{*}$ (-blueness to +yellowness) are the chromaticity coordinates. The $a^{*}$ and $b^{*}$ values were converted to chroma $\left[C=\left(a^{* 2}+b^{* 2}\right)^{1 / 2}\right]$ and hue angle $\left[h=\tan ^{-1}\left(b^{*} / a^{*}\right)\right]$. Before measurement, the equipment was calibrated against a standard white tile. Skin colour was measured at three positions on the fruit surface, on the shoulder, at the equator and at the base. Three readings from each fruit were averaged prior to data analysis. 
Flesh firmness of capsicum fruits was measured using a Digital Firmness Tester (DFT 14, Agro Technologie, France) fitted with a $5 \mathrm{~mm}$ diameter stainless probe at the locular space and carpel wall of the whole fruit at the equatorial region (Tadesse et al. 2002). Firmness was reported in kilogram-force $/ \mathrm{cm}^{2}$ (kgf $\mathrm{cm}^{-2}$ ).

Measurements of ascorbic acid, total soluble solids (TSS) and pH: Ascorbic acid content was estimated by 2,6-dichlorophenolindophenol titration following the method by Ranganna (1986), and results were expressed as $\mathrm{mg}_{100 \mathrm{~g}^{-1}}$ fresh weight. The total soluble solids and $\mathrm{pH}$ of the juice were determined by using hand-held Kruss refractometer (Model HR 900, SN 1200793, brix range 0-90\% at $20^{\circ} \mathrm{C}$, Germany) and glass electrode $\mathrm{pH}$ meter (Delta 320, Mettler, Shanghai), respectively.

Evaluation of sensory attributes: Sensory evaluation, based on general visual appeals, colour, crispiness, flavour, taste, and visible structural integrity was conducted using a 7-point hedonic scale (Hernandez-Munoz et al., 2008). The scores were: $7=$ like extremely; $6=$ like very much; $5=$ like moderately; $4=$ neither like nor dislike; $3=$ dislike moderately; $2=$ dislike very much and $1=$ dislike extremely. Fruit scored above 4 was considered acceptable. Sensory evaluation was performed by a panel of judges consisting of 10 scientific personnel including both male and female members. Different preferences as indicated by scores were evaluated by statistical methods.

Statistical analysis: The data were subjected to analysis of variance (ANOVA) using the CropStat Statistical Software version 7.2. The results showing significant differences were then subjected to mean separation using Tukey's Studentized Range (HSD) Test at $P \leq 0.05$. Analyzed data were graphically plotted using Sigma-plot 8.2 software.

\section{Results and Discussion}

Fruit length, diameter, and weight: Both length and diameter of capsicum fruits significantly $(P \leq 0.05)$ increased with the increase of harvesting time from anthesis (Fig. 1). The longest fruit $(12.28 \mathrm{~cm})$ was harvested after 48 days of anthesis, which was significantly similar $(P \leq 0.05)$ with fruits that harvested on 42 and 45 DAA. Whereas, the shortest fruits $(9.78 \mathrm{~cm})$ were obtained from harvesting after 33 days of anthesis. Similarly, fruits with maximum diameter of $9.14 \mathrm{~cm}$ were harvested after 48 days of anthesis, which was statistically similar with the fruits harvested after 45 days of anthesis. In an experiment Tadesse et al. (2002) found that capsicum fruit (cv. Domino) had attained almost $75 \%$ of its final length after three weeks of anthesis, but continued to elongate at a slower rate until 10 weeks after anthesis. 


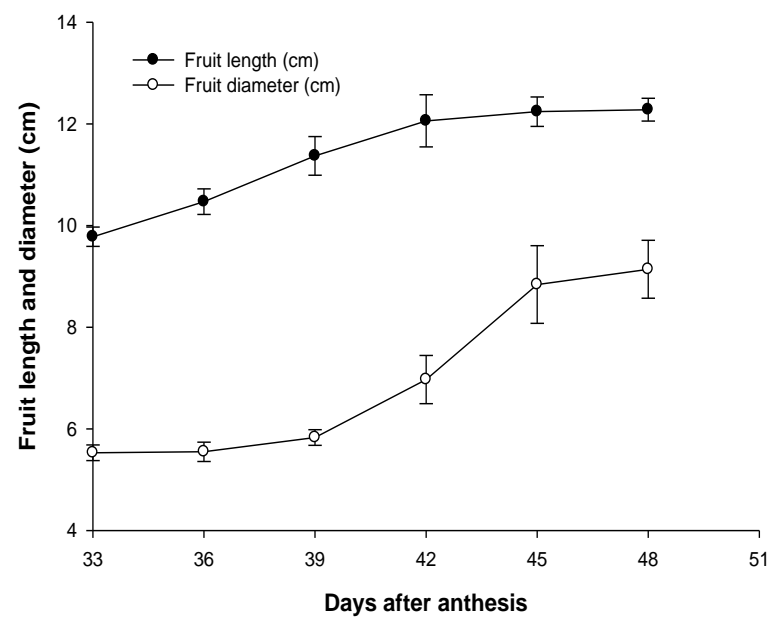

Fig. 1. Changes in fruit length and diameter in capsicum at different days after anthesis. Vertical bars indicate standard deviation.

Capsicum fruits under this experiment showed gain in weight as extend the harvest time from flower anthesis (Fig. 2). The lighter fruits (78.26 g) were harvested after 33 days of anthesis, which increased steadily until 39 DAA. After this period, fruit weight was increased sharply with extend the harvesting time until 45 DAA $(191 \mathrm{~g})$. However, the maximum fruit weight of $192 \mathrm{~g}$ was obtained after 48 days of anthesis, which was statistically similar $(P \leq 0.05)$ with fruit weight gained after 45 days of anthesis. Tadesse et al. (2002) reported that sweet pepper (cv. Domino) fruit fresh weight was linearly increased until eight weeks after anthesis.

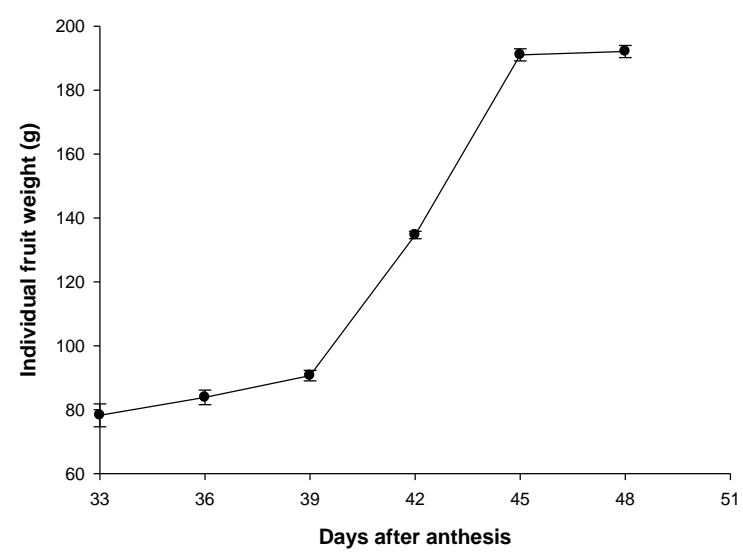

Fig. 2. Changes in individual fruit weight in capsicum at different days after anthesis. Vertical bars indicate standard deviation. 
Fruit surface colour: Surface colour changes of capsicum fruits were monitored by measuring lightness $\left(\mathrm{L}^{*}\right)$, chroma $\left(\mathrm{C}^{*}\right)$, and hue angle $\left(\mathrm{h}^{\circ}\right)$ during harvesting periods. Values are presented in Fig. 3a-b, respectively. The intensity of green colour of fruit skin was slowly decreased with extend the harvesting time and turned to lighter green as evidenced by increasing values of $\mathrm{L}^{*}$ and $\mathrm{C}^{*}$ (Fig. 3a). The initial values of $\mathrm{L}^{*}$ and $\mathrm{C}^{*}$ were 35.12 and 21.52 , respectively, were recorded in fruits that harvested after 33 days of anthesis which remained rather unchanged until 39 DAA. After that time, both were gradually increased and reached to 39.46 and 24.49 , respectively, after 48 days of anthesis. There was no significant difference regarding the changes in $\mathrm{L}^{*}$ and $\mathrm{C}^{*}$ values among fruits harvested after 42,45 , and 48 days of anthesis. Results of the present study are partially supported by the findings of Tadesse et al. (2002) who observed a little increased in lightness and chroma of capsicum fruit during growth and development.

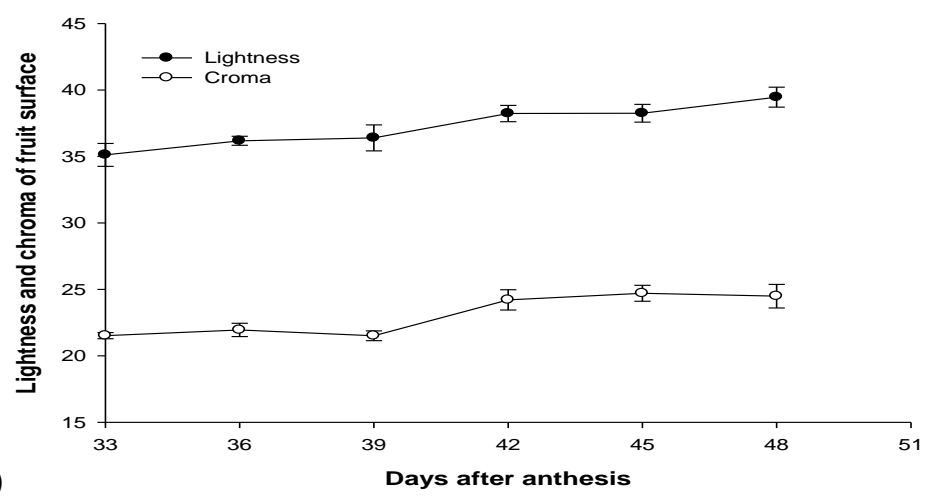

(a)

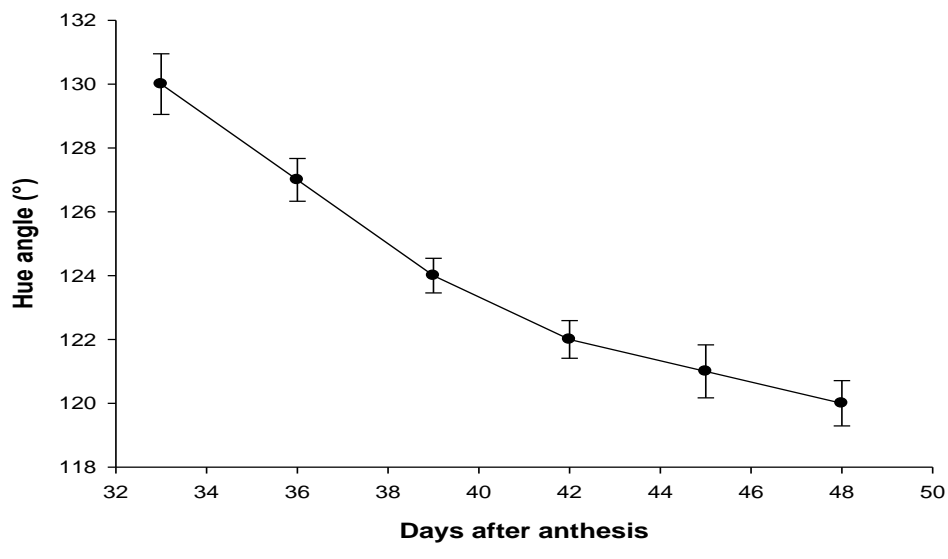

(b)

Fig. 3. Changes in external colour (a) lightness and chroma; (b) hue angle of capsicum fruit at different days after anthesis. Vertical bars indicate standard deviation. 
Hue angle is an indicator of colour change from green to yellow and red. In this study, the degree of hue angle was recorded 130 in fruit surface that harvested after 33 days of anthesis (Fig. 3b). After that, capsicum fruit showed a significant decrease in hue angle with extent the harvest period and attained the minimum level of 120 after 48 days of anthesis. This fall in hue value indicated that the intensity of green colour slowly decreased with maturity and turned to lighter green. Tadesse et al. (2002) found that the hue angle of capsicum fruits (cv. Domono) decreased sharply after seven weeks of anthesis that reflecting the colour change from green to red, which corroborates the present findings. The colour changes in sweet pepper correspond to a decrease in chlorophyll and an increase in carotenoid synthesis (Pretel et al., 1995).

Flesh firmness: Flesh firmness is a critical quality attribute in the consumer acceptability of fresh fruits and vegetables. The firmness of capsicum flesh that harvested after 33 days of anthesis was recorded $7.14 \mathrm{kgf} \mathrm{cm}^{-2}$ (Table 1), which progressively increased with extend the harvesting time from anthesis and reached the maximum firmness of $14.5 \mathrm{kgf} \mathrm{cm}^{-2}$ after 48 days of anthesis. Significantly similar $(P \leq 0.05)$ firmness was found in fruits that harvested after 45 and 42 DAA. Result of this study supported the findings of Tadesse et al. (2002), who reported that pericarp thickness of capsicum increased with fruit age and was positively correlated with fruit firmness. The relationship between pericarp thickness and fruit firmness was also confirmed by Gu et al. (1999) in Jalapeno pepper.

Table 1. Changes in different physicochemical characters of capsicum fruits after different days of anthesis.

\begin{tabular}{c|c|c|c|c|c|c}
\hline $\begin{array}{c}\text { Days after } \\
\text { anthesis }\end{array}$ & $\begin{array}{c}\text { Fruit } \\
\text { firmness } \\
\left(\mathrm{Kgf} \mathrm{cm}^{-2}\right)\end{array}$ & $\begin{array}{c}\text { Ascorbic } \\
\text { acid } \\
(\mathrm{mg} / 100 \mathrm{~g})\end{array}$ & $\begin{array}{c}\text { Total } \\
\text { soluble } \\
\text { solids (\%) }\end{array}$ & $\mathrm{pH}$ & $\begin{array}{c}\text { Fruit dry } \\
\text { matter (\%) }\end{array}$ & $\begin{array}{c}\text { Storage life } \\
(\text { Days })\end{array}$ \\
\hline 33 & $7.14 \mathrm{~d}$ & $68.0 \mathrm{a}$ & $4.0 \mathrm{~d}$ & 5.79 & $5.19 \mathrm{c}$ & $9.7 \mathrm{~d}$ \\
36 & $10.0 \mathrm{c}$ & $63.5 \mathrm{~b}$ & $4.2 \mathrm{c}$ & 5.75 & $5.42 \mathrm{c}$ & $15.7 \mathrm{c}$ \\
39 & $11.1 \mathrm{c}$ & $61.0 \mathrm{~b}$ & $4.4 \mathrm{c}$ & 5.73 & $6.14 \mathrm{~b}$ & $18.6 \mathrm{~b}$ \\
42 & $12.3 \mathrm{~b}$ & $58.5 \mathrm{c}$ & $4.7 \mathrm{~b}$ & 5.72 & $6.62 \mathrm{~b}$ & $20.3 \mathrm{a}$ \\
45 & $12.7 \mathrm{~b}$ & $58.0 \mathrm{c}$ & $4.9 \mathrm{~b}$ & 5.72 & $7.21 \mathrm{ab}$ & $21.2 \mathrm{a}$ \\
48 & $14.5 \mathrm{a}$ & $56.0 \mathrm{~d}$ & $5.0 \mathrm{a}$ & 5.71 & $7.35 \mathrm{a}$ & $21.3 \mathrm{a}$ \\
\hline F-value & $*$ & $*$ & $*$ & $\mathrm{~ns}$ & $*$ & $*$ \\
CV $(\%)$ & 4.9 & 2.6 & 1.4 & 0.9 & 4.0 & 5.7 \\
\hline
\end{tabular}

Values in each column followed by the same letter (s) are not significantly different at $5 \%$ level.

*Significant at $5 \%$ level; ns= Not significant. 
Ascorbic acid, TSS, and pH: It is evident that the length of harvesting time induced significant variation in ascorbic acid content of capsicum fruits (Table 1). The ascorbic acid content was significantly higher $(68 \mathrm{mg} / 100 \mathrm{~g})$ in younger fruits that harvested after 33 days of anthesis. But with the extend of harvest length, the content gradually decreased and reached the minimum level of 56 $\mathrm{mg} / 100 \mathrm{~g}$ after 48 days of anthesis. There was no statistical difference $(P \leq 0.05)$ with regard to ascorbic acid contents in fruits harvested on 42 and 45 DAA. The losses of ascorbic acid can be continued through maturity, postharvest handling, processing, cooking, and storage of fruits and vegetables (Lee and Kader, 2000). Results of the present study are in agreement with Nagy (1980), who reported that immature fruits contained the highest concentration of ascorbic acid, whereas mature fruits contained the least.

The changes in TSS content of capsicum fruits with harvesting length is presented in Table 1. The TSS of fruit samples harvested after 33 days of anthesis was fairly low (4\%), which was slowly increased with increase of harvesting time. The TSS content reached the maximum level of 5\%, when fruits were harvested after 48 days of anthesis. No significant $(P \leq 0.05)$ difference was observed regarding the TSS content in fruits that harvested between 45 and 48 DAA. The increase in TSS of sweet pepper fruit with maturity is probably a result of increased hexose sugar accumulation during fruit ripening (Nielsen et al., 1991) as there is a close positive correlation between the rise in TSS and soluble sugars (Mendlinger et al., 1992). Results of the present experiment are in agreement with Tadesse et al. (2002) who found that the TSS of capsicum increased slightly from 5 to $6 \%$ during the period 2 to 6 week after anthesis.

The changes in $\mathrm{pH}$ of capsicum fruits as a function of different harvesting time are shown in Table 1. From the results, it was found that pulp $\mathrm{pH}$ of capsicum fruit was not affected by different harvest maturity. The $\mathrm{pH}$ ranged 5.71 to 5.79 was found during harvesting from 33 to 48 DAA, which was not significantly different among harvesting times. Similar results were also found by Fox et al. (2005) who reported that capsicum $\mathrm{pH}$ was not affected by different harvesting time, which ranged 4.9 to 5.1.

Dry matter content and shelf life: Dry matter content of capsicum was found lower $(5.19 \%)$ in fruits that harvested after 33 days of anthesis and then steadily increased as extend the harvest duration (Table 1). The maximum dry matter $(7.35 \%)$ was gained by fruits that harvested after 48 days of anthesis. Significantly $(P \leq 0.05)$ similar dry matter was found in fruits that harvested on 45 DAA.

As changes in the dry matter content over harvesting period, similar trend was also observed for shelf life of fruits. The shelf life of 33 day's harvested fruits was only 9.7 days at $12{ }^{\circ} \mathrm{C}$ and $88 \pm 5 \% \mathrm{RH}$, which steadily increased with 
increase the harvest duration and reached the maximum shelf period of 21.3 days for fruits that harvested after 48 days of anthesis (Table 1). However, no significant $(P \leq 0.05)$ differences were observed in regarding the shelf life among fruits harvested after 45 and 48 days of anthesis. In this study, it was found that younger fruits which harvested after 33-36 days of anthesis had poor shelf life compared to the mature fruits. Results of this study are in agreement with Wills et al. (2007) who stated that respiration rate per unit weight is highest for the immature fruit or vegetables and then steadily declines with age and product that respires very fast will have a short storage life and vice versa.

Sensory evaluation: Sensory data for capsicum quality based on visual appearance and organoleptic taste are presented in Table 2. Out of seven, the highest score (6.8) for overall sensory attributes was achieved by the fruits that harvested after 45 days of anthesis, which was significantly $(P \leq 0.05)$ similar with fruits harvested after 42 days (6.6). At this stage of maturity, fruits were crisper, attained maximum flavour and taste with attractive skin colour. Therefore, judges showed a significant preference for fruits that harvested after 45 days of anthesis which obtained mean acceptance scores between 'like very much' and 'like extremely' on the hedonic scale.

Table 2. Overall acceptability based on visual appearance and organoleptic taste of capsicum fruit harvested at different maturity stage.

\begin{tabular}{c|c}
\hline Days of maturity & Overall sensory score (1-7) \\
\hline 33 & $4.8 \pm 0.45 \mathrm{~d}$ \\
36 & $5.0 \pm 0.00 \mathrm{c}$ \\
39 & $6.2 \pm 0.45 \mathrm{~b}$ \\
42 & $6.6 \pm 0.45 \mathrm{a}$ \\
45 & $6.8 \pm 0.55 \mathrm{a}$ \\
48 & $6.2 \pm 0.45 \mathrm{~b}$ \\
\hline
\end{tabular}

Means within column with different letter are significantly different $(P \leq 0.05)$

Maturity of sweet pepper fruit was determined by a combination of different attributes. In this study, TSS, ascorbic acid content, surface colour change, and firmness were found to be good indicators for sweet pepper fruit maturity. Based on the results of the present study, sweet pepper fruits of the var. 'BARI Misti Morich-1' reached physiological maturity at 45 DAA. At this stage of maturity, fruit attained $12.24 \mathrm{~cm}$ length, $8.84 \mathrm{~cm}$ diameter, and $191 \mathrm{~g}$ in weight. Moreover, fruit contained $58 \mathrm{mg} / 100 \mathrm{~g}$ of ascorbic acid, which is a very important quality attribute of fresh capsicum. Besides, fruits were more crispy, glossy, pleasant flavoured, and also tasty at this stage. 


\section{References}

Bautista, O. K. 1990. Postharvest Technology for Southeast Asian Perishable Crops. A Simplified Guide. Technology and Livelihood Resource Centre, UPLB, College Laguna, Philippines.

Bhatt, R. M., R. N. K. Srubuvasa and N. Anand. 1999. Response of bell pepper to irradiance photosynthesis, reproductive attributes and yield. Indian J. Hort. 56 (1): 62-66.

Boonyakiat, D., P. M. Chen, R. A. Spotts and D. G. Richardson. 1987. Effect of harvest maturity on decay and postharvest life of 'd'Anjou' pear. Scientia Hortic. 31: 131-139.

Fox, A. J., D. D. Pozo-Insfran, J. H. Lee, S. A. Sargent and S.T. Talcott. 2005. Ripeninginduced chemical and antioxidant changes in bell peppers as affected by harvest maturity and postharvest ethylene exposure. Hort Science 40(3): 732-736.

Gu, Y. S., L. R. Howard and A. B. Wagner. 1999. Physicochemical factors affecting firmness of pasturized Jalapeno pepper rings. J. Food Quality 22: 619-629.

Hernandez-Munoz, P., E. Almenar, V. D. Valle, D. Velez and R. Gavara. 2008. Effect of chitosan coating combined with postharvest calcium treatment on strawberry (Fragaria $x$ ananassa) quality during refrigerated storage. Food Chem. 110: 428-435.

Howard, L. R., R. T. Smith, A. B. Wagner, B. Villalon and E.E. Burns. 1994. Provitamin A and ascorbic acid content of fresh pepper cultivars (Capsicum annuum) and processed Jalapenos. J. Food Sci., 59: 362-365.

Lee, S. K. and A. A. Kader. 2000. Preharvest and postharvest factors influencing vitamin C content of horticulture crops. Postharvest Biol. Technol. 20: 207-220.

Lin, W. C., J. W. Hall and M. E. Saltveit Jr. 1993. Ripening stage affects the chilling sensitivity of greenhouse grown peppers. J. Am. Soc. Hort. Sci. 118: 791-795.

Manandhar, J. B., G. L. Hartman and T. C. Wang. 1995. Anthracnose development on pepper fruits with Colletotrichum gloeosporiodes. Plant Dis. 79: 380-383.

Mendlinger, S., A. Benzioni, S. Huyskens and M. Ventura. 1992. Fruit development and postharvest physiology of Cucumis metuliferus Mey, a new crop plant. J. Hort. Sci. 67: 489-493.

Meredith, F. I., J. A. Robertson and R. J. Horvat. 1989. Changes in physical and chemical parameters associated with quality and postharvest ripening of harvested peaches. $J$. Agric. Food Chem. 37: 1210-1214.

Nagy, S. 1980. Vitamin C contents of citrus fruit and their products: a review. J. Agric. Food Chem. 28: 8-18.

Pareek, O. P. 2001. Ber. International Centre for Under-utilized Crops, Southampton, SO17 IBJ, UK.

Pretel, M. T., M. Serrano, A. Amoros, F. Riquelme and F. Romojaro. 1995. Noninvolvement of ACC and ACC oxidase activity on pepper fruit ripening. Postharvest Biol. Technol. 5: 295-302.

Ranganna, S. 1986. Handbook of Analysis and Quality Control for Fruit and Vegetable Products. Second ed. Tata McGraw-Hill, New Delhi, India. Pp. 1112. 
Saha, S. R. and M. A. Salam. 2004. Modern technologies of sweet pepper cultivation. Horticulture Research Centre, BARI, Gazipur-1701, Bangladesh. Pp. 13.

Sanchez, V. M., F. J. Sundstrom, G. N. McClure and N. S. Lang. 1993. Fruit maturity, storage and postharvest maturation treatments affect bell pepper (Capsicum annuиm L.) seed quality. Sci. Hortic. 54: 191-201.

Serrano, M., M. C. Martinez-Madrid, F. Riquelme and F. Romojaro. 1995. Endogenous levels of polyamines and abscisic acid in pepper fruits during growth and ripening. Physiol. Plantarum 95: 73-76.

Tadesse, T., E. W. Hewett, M. A. Nichols and K. J. Fisher. 2002. Changes in physicochemical attributes of sweet pepper cv. Domino during fruit growth and development. Sci. Hortic. 93: 91-103.

Wills, R., B. McGlasson, D. Graham, and D. Joyce. 1998. Postharvest. CAB International, Wallingford, OXON, OX10 DE, UK.

Wills, R., B. McGlasson, D. Graham and D. Joyce. 2007. Postharvest: An introduction to the physiology and handling of fruit, vegetables and ornamentals. 5th ed. UNSW Press, Australia. 